\title{
Design and Fabrication of a Manually Operated Vegetable Leaf Slicing Machine
}

\author{
${ }^{* 1}$ IKPOZA, E; ${ }^{2}$ USIOBAIFO, EJ; ${ }^{3}$ ERHUNMWUN, ID \\ Department of Production Engineering, University of Benin, Benin City, Nigeria. \\ *Corresponding Author Email: emmanuel.ikpoza@uniben.edu; Other Authors Email: edosabrainu@gmail.com; \\ iredia.erhunmwun@uniben.edu
}

\begin{abstract}
This paper entails the design and fabrication of a manually operated vegetable leaf slicing machine. The developed machine consists of a hopper, the cutter housing, the cutting blades, the rotating shaft, and a wooden handle. The machine was designed to enhance the hygienic slicing of vegetable leaf materials and for prevention of knife-related injuries for both domestic and commercial use. The machine was tested with a slicing efficiency of $95.52 \%$ with a provision of an alternative quick vegetable cutting process with no injuries, no electric power supply and with little or no noise to the operating environment.
\end{abstract}

\section{DOI: https://dx.doi.org/10.4314/jasem.v25i2.9}

Copyright: Copyright $\odot 2021$ Ikpoza et al. This is an open access article distributed under the Creative Commons Attribution License (CCL), which permits unrestricted use, distribution, and reproduction in any medium, provided the original work is properly cited.

Dates: Received: 12 December 2020; Revised: 26 January 2021; Accepted: 12 February 2021

Keywords: Vegetables, slicing, cutting blade, knives, hopper

According to Smith (2013), cooking/kitchen knives has constituted $36 \%$ of knife-related injuries treated in United States emergency departments, between 1990 and 2008. Vegetables consist of large groups of plants consumed as food by both human and animals. Vegetables can be perishable when fresh but be preserved by a number of processing methods. They are excellent source of certain minerals and vitamins and are often the main source of dietary fibre. Vegetables can be divided into edible roots (e.g., Carrots and potatoes), stem (Asparagus and celery), leaf (lettuce, pumpkin, spinach and fruited pumpkin), immature flower bud (broccoli and Brussels sprouts) and fruits (tomatoes and cucumbers) etc., (Britannica encyclopaedia, 2008). From time immemorial, knives and graters were the major tools for slicing and grating vegetables such as, pepper, carrot, onions, and so on. However, it was noticed that, usually more time is required for slicing vegetables using knives, and in some cases, injuries occur. Vegetable slicing with knife is known to be hazardous, increasing the number of people who gets hurt while using knives in slicing their vegetables (Cliver et al 1994). But as time went on, technology began to advance and different manufacturers began to research on new and more efficient ways of achieving the same goal while saving time and associated hazards caused by knife usage (Bird, 1995). Awili et al 2009, designed a manual vegetable slicing machine. It was however not specified what type of vegetable the simple machine was designed to slice. Shittu et al (2017), developed a motorised tomato cutter with an output capacity of $468 \mathrm{~kg} / \mathrm{h}$, percentage loss of $28.40 \%$, and slicing efficiency of $60.34 \%$.

\section{MATERIALS AND METHODS}

In this design, stainless steel was used. The stainless steel was used in the frame, the cutter, the cutter housing and in part of the handle due to its ability to resist corrosion, thereby preventing food contamination. The different parts of the Vegetable Slicing Machine were fabricated according to design specifications and assembled together mainly by welding, and use of nuts and bolts for ease of assembly and disassembly. Detailed Engineering drawing. There were various components that made up the whole design concept (Figures 1, 2, 3) of the manual vegetable leaf slicing machine. These parts are:

Handle: The handle is connected to a rotating shaft which rotates the cutter as the impeller pushes the vegetables to the cutter.

Impeller: The impeller is a component part of the vegetable slicing machine whose main function is to push the vegetables towards the rotating cutter.

Rotating Shaft: The rotating shaft is connected to the handle which aid the cutter (blade) to easily rotate in order to cut the vegetables

*Corresponding Author Email: emmanuel.ikpoza@uniben.edu 
Cutter: Its function basically is to cut the vegetables being introduced by the impeller into smaller pieces

Outer Cover: The outer cover made of stainless steel is used to enclose the cutter (blade). A small diameter hole is drilled at the middle of the cover. It is fitted screws.

Main Body: This is the body (frame) of the design with the various components assembled together.

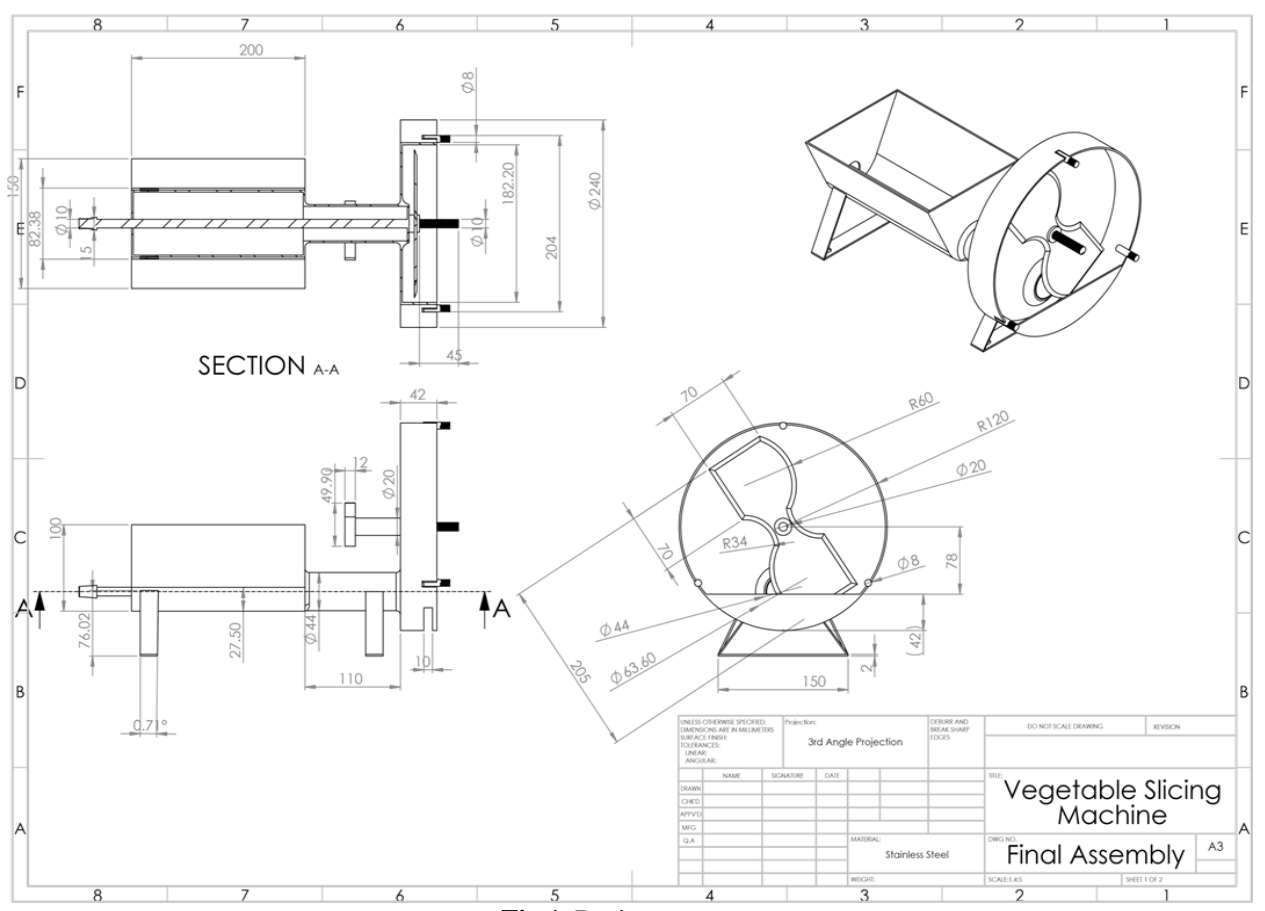

Fig 1. Design concepts

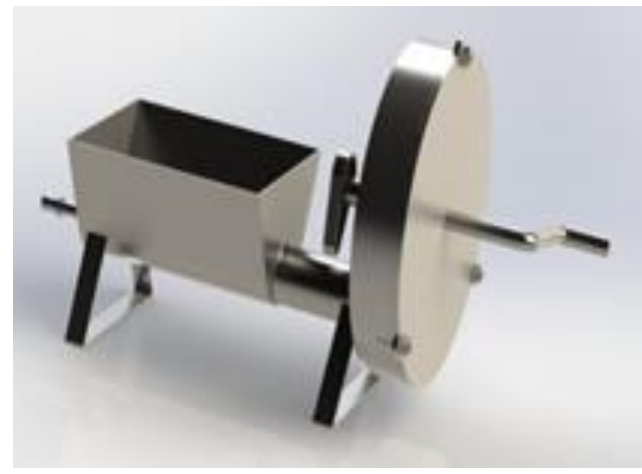

Fig 2. Assembled Machine

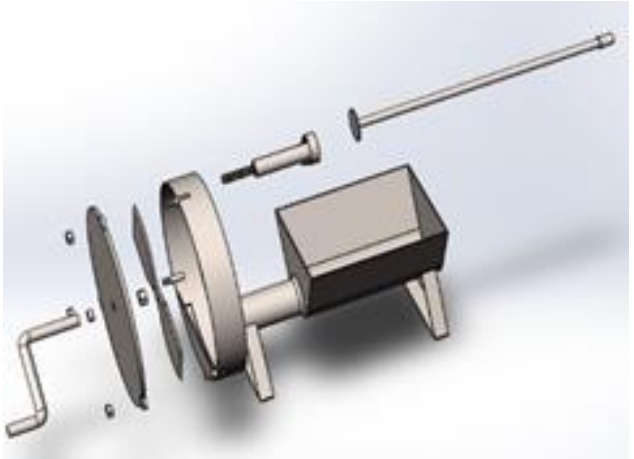

Fig 3. Exploded view
Mode of Operation: The machine in bolted securely onto a flat platform by means of nuts and bolts. The plucked vegetables forming a bunch are introduced by hand into the receiving compartment. With the aid of the impeller, the vegetables are pushed into the cutting compartment through the cylindrical channel. The vegetables are cut by means of the rotating stainless steel cutter blades as it comes in contact with the vegetables as they exit the cylindrical chamber into the cutting compartment. The rotary motion of the cutter blade is produced by the manual circular turning of the handle. The rotating shaft serves as a support and gives stability to the cutter. The size of cut required is obtained by adjusting the feed rate of the impeller.

Components Design Vegetable compartment design: The volumetric capacity for the vegetable compartment was calculated in relation to the volume of material it occupied. The compartment was designed to contain about two bunches of vegetables per unit operation.

The volume was calculated from the relationship

$$
\rho=\frac{m}{v}
$$


Where, $v=$ volume of material in $\mathrm{m}^{3}, m=$ Mass of the vegetable in $\mathrm{kg}=0.7 \mathrm{~kg}$ (Approx.), $\rho=$ Bulk density of vegetables $=561 \mathrm{~kg} / \mathrm{m}^{3}$

$$
\text { Therefore, } v=0.0012 \mathrm{~m}^{3}
$$

Knife thickness design: Selection of right thickness of slicing knife is very essential as it directly affects the slicing effectiveness. The thickness of slicing knife was calculated using expression if given by Khurmi and Gupta (2005):

$$
t=\frac{W_{k}}{L_{K} \times . B_{k} \times g \times\left(\rho_{k}-\rho_{v}\right)}
$$

Where $\mathrm{t}=$ thickness $(\mathrm{m}) ; W_{k}=$ Knife Weight $=250 \mathrm{~g}=$ $0.25 \mathrm{~kg} ; L_{k}=$ knife length $=20.15 \mathrm{~cm}=0.2015 \mathrm{~m}$ and $B_{k}$ $=$ knife width $=84 \mathrm{~mm}=0.084 \mathrm{~m}$

$\rho_{k}=$ knife density $=7700 \mathrm{~kg} / \mathrm{m}^{3}$ (Stainless Steel)

$\rho_{v}=$ vegetable density $=561 \mathrm{~kg} / \mathrm{m}^{3}$ (measured).

$t=0.00021 \mathrm{~m}=0.2 \mathrm{~mm}$ (Approx.)

It should however be noted that we could not readily obtain a stainless-steel material with the calculated thickness of $0.2 \mathrm{~mm}$. Therefore, a thickness of $1 \mathrm{~mm}$ was used during fabrication.

Slicer stand thickness design: For the slicer stand we use the slender ratio formular:

$$
F=\frac{\pi^{2} E I}{(K L)^{2}}
$$

Where $F=$ maximum force

$$
F=W_{t c}+W_{h f}
$$

Where $W_{t c}=$ Entire vegetable compartment weight inclusive of knife $=5.44 \mathrm{~N}$ (measured); $W_{h f}=$ average human effort exerted by hand which is given as $12.38 \mathrm{~N}$ (Bernhard \& Roemer, 1969)

$$
F=W_{t c}+W_{h f}=17.82 \mathrm{~N}
$$

Where $E=$ modulus of elasticity (stainless steel) $=186$ to $200 \mathrm{kN} / \mathrm{mm}^{2}$ and $I=$ Area moment of Inertia

$$
I=\frac{b d^{2}}{12}
$$

Where $b=d$

$$
I=\frac{d^{4}}{12}
$$

Where $K=$ effective length factors whose value depends on the condition of the support.

Both ends pinned $K=1$

Both ends fixed $K=0.5$

One fixed and the other is free $K=2$

Where $\mathrm{L}=$ length of the column ( slicer stand $)=0.4 \mathrm{~m}$. This was selected for ergonomic reason.

$$
\begin{aligned}
& \text { From }(5), I=\frac{F(K L)^{2}}{\pi^{2} E} \\
& I=\frac{F(K L)^{2}}{\pi^{2} E}=\frac{d^{4}}{12} \\
& d=\sqrt[4]{\frac{12 F(K L)^{2}}{\pi^{2} E}}
\end{aligned}
$$

$d=\sqrt[4]{\frac{12 \times 17.82 \times(0.5 \times 0.4)^{2}}{3.14^{2} \times 200 \times 10^{3}}}$

$d=0.0456 \mathrm{~m}=46 \mathrm{~mm}$ (Approx.)

Efficiency of the Machine: Average size of Original Vegetable leaf $=91.6 \mathrm{~mm}$

Average size of sliced Vegetable leaf $=4.1 \mathrm{~mm}$

Slicing Efficiency $=\frac{\text { Original }- \text { final }}{\text { Original }} \times \frac{100}{1}=$ $\frac{91.6-4.1}{91.6} \times \frac{100}{1}=95.52 \%$

From the results, a slicing efficiency of $95.52 \%$ was achieved for the machine. This implies that the newly developed machine is reliable.

Table 1: Bill of Engineering Materials and Evaluation

\begin{tabular}{llll}
\hline S/N & Material & Quantity & $\begin{array}{l}\text { Net cost } \\
\text { (Naira) }\end{array}$ \\
\hline 1 & stainless steel metal & $4 \mathrm{ft}$ x4ft & 8,500 \\
2 & Stainless steel electrode & 28 & 5,600 \\
3 & Cutting abrasive & 3 & 3,000 \\
4 & Angle grinder abrasive & 3 & 650 \\
5 & Impeller & 1 & 550 \\
6 & Blade & 1 & 1,500 \\
7 & Bolt and nuts & 5 & 1,950 \\
\hline TOTAL & & $\mathbf{2 1 , 7 5 0}$ \\
\hline
\end{tabular}




\section{RESULT AND DISCUSSION}

The vegetable slicing machine as designed and manufactured is effective and efficient in its function. Dimensions of 10 samples of the original vegetable leaves were taken before being sliced. Also dimensions of the sliced vegetable leaves from the machine were taken. The experimental results are as shown in Table 2.

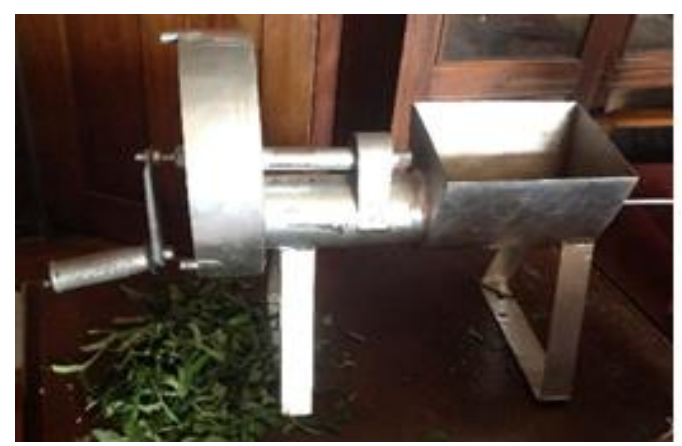

Fig 3. Machine with sliced vegetables
The result of evaluation gave slicing efficiency 95.52 $\%$. Thus, this work provides an alternative to the existing conventional use of knives. The cutter is fully enclosed thereby eliminating the risk of injury caused by direct exposure of hands to the cutting edge of the knives.

It was seen that the sliced vegetable leaves obtained from using this machine was way better than those obtained from the traditional method, as the one obtained from this machine was evenly sliced. The total cost of the materials used in the fabrication of this machine is as shown in Table 1.

This cost is exclusive of the cost for labour. It is pertinent to add that some of the materials used for the fabrication may not be adjudged as the best in the market but were selected based on the constraint of cost. This machine will therefore help to produce sliced vegetable faster and safer.

\begin{tabular}{llllllllllll} 
Table 2: Experimental results for slicing efficiency \\
\hline S/N & 1 & 2 & 3 & 4 & 5 & 6 & 7 & 8 & 9 & 10 \\
\hline Size of Unsliced Leaf $(\mathrm{mm})$ & 72 & 74 & 87 & 110 & 80 & 100 & 90 & 105 & 85 & 113 \\
Size of Sliced Leaf $(\mathrm{mm})$ & 9 & 8.5 & 7 & 6 & 5 & 2 & 2 & 3 & 3 & 2.5 \\
\hline
\end{tabular}

Conclusion: The manual vegetable slicing machine has been designed, fabricated and evaluated. It is manually operated and therefore will save domestic power consumption. It is gratifying to know that it has been proven that this machine performs its function satisfactorily. Time consumption is less when compared to manual cutting using knives. This work has tried in providing the desired output.

\section{REFERENCES}

Awili CPN; Omidiji BV; Awili II (2009). Design of Manual Vegetable Slicing Machine: Nig. J. Res. Product. 15 (2) 1-10

Bird J0 (1995). Science for engineering, N. Y. Kent Newness

Britannica encyclopedia, (2008): Definition of vegetables; leafy and non-leafy vegetables

Cliver OD; Ak NO; Kasper CW (1994): Cutting Boards of Plastic and Wood Contaminated Experimentally with Bacteria. J. Food Protect. 57 (1) $16-22$
Kamaldeen OS; Arowora KA; Abioye JS; Awagu EF (2016). Modification of Manually Operated Tomato Slicing Machine: Inter. J. Eng. Sci. Computing: 6 (7) 1933-1938

Khurmi RS; Gupta JK (2005). A Textbook of Machine Design (S.I. Units) Published by Eurasia Publishing House (PVT) Ltd, Ram Nagar, New Delhi.

Smith GA (2013), Knife-related injuries treated in United States emergency departments, 19902008.

https://www.ncbi.nlm.nih.gov/pubmed/23849364 , accessed $19^{\text {th }}$ January, 2018

Shittu SK; Bello M; Dangora ND (2017). Development of a motorized tomato (solanumlycopersicum l.) Slicer: Arid Zone. J. Eng. Technol. Environ. 13(2):197-208 